\title{
PARA UNA HISTORIA DE LOS NOBLES SIN ARCHIVOS. SOBRE LAS FUENTES DOCUMENTALES PARA ESTUDIAR la nobleza castellana en la Plena Edad Media. EL CASO DE LOS RoJAs (1200-1350)
}

\author{
Ignacio Álvarez Borge ${ }^{1}$ \\ Universidad de La Rioja
}

Recibido: 6 de noviembre de 2020

Aceptado: 21 de enero de 2021

\begin{abstract}
Resumen:
Debido a las características de la documentación conservada, el estudio de la nobleza en Castilla en la Plena Edad Media exige la consulta de numerosos fondos documentales, puesto que apenas hay archivos nobiliarios en ese período -los pocos que se conocen se han conservado en archivos monásticos-. De esa forma, la reconstrucción genealógica de las familias y grupos familiares y de los dominios nobiliarios es sumamente laboriosa y exige la consulta de documentación dispersa e inconexa. En este artículo se explora la documentación conservada para estudiar un grupo familiar muy amplio, los Rojas, entre aproximadamente 1200 y 1350. Se analiza la procedencia de los documentos y sus tipos desde el punto de vista del análisis histórico.
\end{abstract}

\section{Palabras clave:}

Castilla, Nobleza, Rojas, Plena Edad Media, Archivos.

\begin{abstract}
:
Due to the characteristics of the preserved documentation, the study of the nobility in Castile in the Central Middle Ages requires the consultation of numerous collections of charters, since there are hardly any noble archives in that period - the few that are known have been conserved in monastic archives -. For this reason, the reconstruction of kinship ties and lordships and properties is extremely laborious and requires the consultation of scattered and disconnected documentation. This article explores the preserved documentation to study a very large family group, the Rojas, between approximately 1200 and 1350. The origin of the documents is analyzed and also their types from the point of view of historical analysis.
\end{abstract}

\section{Keywords:}

Castile, Nobility, Rojas, Central Middle Ages, Archives.

\footnotetext{
1 Departamento de Ciencias Humanas. Universidad de La Rioja. Correo electrónico: ignacio.alvarez@, unirioja.es. ORCID: http://orcid.org/0000-0002-7468-1334.
} 


\section{Sommario:}

A causa delle caratteristiche della documentazione conservata, lo studio della nobiltà in Castiglia nel pieno medioevo richiede la consultazione di numerose raccolte documentarie, perque per quel periodo non esistono quasi archivi nobili (i pochi che si conoscono sono stati conservati negli archivi monastici). In questo modo, la ricostruzione della genealogia delle famiglie e dei gruppi familiari e di proprietà e domini nobiliari è estremamente laboriosa e richiede la consultazione di documentazione sparsa e sconnessa. Questo articolo esplora la documentazione conservata per studiare un gruppo familiare molto ampio, i Rojas, tra il 1200 e il 1350 circa. Viene analizzato l'origine dei documenti e anche le sue tipologie dal punto di vista dell'analisi storica.

\section{Parole chiave:}

Castiglia, Nobiltà, Rojas, Medioevo pieno, Archivi.

\section{Introducción}

Los especialistas en historia de la nobleza castellana en la Alta y en la Plena Edad Media conocen bien las dificultades que conlleva su estudio por las características de la documentación conservada. En general, podemos decir que no hay archivos nobiliarios para esos siglos (aunque enseguida veremos algunos matices a esa afirmación). En cuanto a los archivos nobiliarios posteriores, conservan pocos documentos anteriores al siglo XIII, los de ese siglo son escasos, comienzan a hacerse más abundantes en el siglo XIV -pero sobre todo a partir de 1350- y ya son numerosos para el siglo XV.

En los últimos años se ha avanzado mucho en la catalogación y puesta a disposición de los investigadores de archivos nobiliarios, sobre todo por la formación del Archivo Histórico de la Nobleza en Toledo desde 1993 y por el trabajo de sus responsables, y también porque otros importantes archivos en manos privadas han avanzado igualmente en ese sentido; sin embargo, aún quedan numerosos archivos de casas nobles todavía difícilmente accesibles y en estado de conservación desconocido ${ }^{2}$. Otra dificultad deriva de que las genealogías nobiliarias conservadas son escasas e inciertas para antes de, digamos, 1300 (también con algunas excepciones) y las reconstrucciones de los genealogistas barrocos también son frecuentemente dudosas para el período anterior al siglo XIV, sobre todo cuando no se trata de las familias más importantes ${ }^{3}$.

\footnotetext{
2 Véase SuÁrez GonzÁlez (ed.), Escritura y sociedad. La nobleza, donde se recopilan varios trabajos recientes sobre archivos y documentación nobiliaria que además aportan bibliografía actualizada. Sobre el Archivo Histórico de la Nobleza (antes Sección Nobleza del Archivo Histórico Nacional), entre otros, LAFUENTE URIÉN, "Los archivos nobiliarios: formación y conservación".

3 Sobre la escritura genealógica nobiliaria en Castilla son muy notables y numerosos los trabajos de Dacosta Martínez, entre ellos, "A propósito de un aparente silencio"; o "La memoria de los antepasados". Merece una atención especial el Livro de Linhagens del conde Pedro de Barcelos, que contiene varias genealogías de familias castellanas y leonesas que todavía esperan estudios detallados (aunque ya hay algunos para algunas de ellas). Véase Mattosso (ed.), Livro de Linhagens do conde d. Pedro. En cuanto a los genealogistas de la Edad Moderna, Alonso López de Haro y Luis Salazar y Castro son los más notables, pero en general cuanto más atrás en el tiempo y cuanto menos poderosos fueran los individuos o familias, más inciertas las genealogías. Sobre los genealogistas de la época moderna, se puede obtener
} 
Con esos problemas, sin embargo, los estudios sobre la nobleza castellana en el período plenomedieval han avanzado significativamente en las últimas décadas por el trabajo muy notable de algunos historiadores. No es lugar para referirse ahora con detalle a la historiografía, pero sí parece necesario recordar, al menos, a los autores que, a nuestro juicio, más y mejor han trabajado en ese sentido ${ }^{4}$. Tras los trabajos de Moxó, que actualizaron el tema de manera muy importante, pero que casi siempre basó sus reconstrucciones en genealogistas modernos ${ }^{5}$, autores como Pascual Martínez Sopena ${ }^{6}$, Carlos Reglero ${ }^{7}$, Miguel Calleja-Puerta ${ }^{8}$, Jaime de Salazar y Acha ${ }^{9}$, Julián Lucas de la Fuente ${ }^{10}$, Simon Barton ${ }^{11}$, Antonio Sánchez de Mora ${ }^{12}$, Simon Doubleday ${ }^{13}$, Andrés Barón ${ }^{14}$, Ghislain Baury ${ }^{15}$ o Inés Calderón ${ }^{16}$ han realizado estudios de referencia en relación con la nobleza castellana y leonesa al norte del Duero en el período del que nos ocupamos aquí, entre 1200 y 1350 aproximadamente, aunque no todos ellos con los mismos planteamientos ${ }^{17}$. También hay que mencionar a José Augusto de Sottomayor Pizarro que, aunque ha estudiado la nobleza portuguesa en ese período, ha aportado ideas y propuestas igualmente aplicables o comparables al ámbito castellano y leonés ${ }^{18}$. Y a ellos se une el importantísimo trabajo de Carlos Estepa sobre Las behetrías castellanas que constituye, a nuestro juicio, la principal obra de referencia por el momento ${ }^{19}$. Por nuestra parte, también hemos realizado algunos estudios sobre el tema; a los relacionados más estrechamente con el objeto de estudio de este artículo aludiremos más adelante. Y también hay que mencionar algunos estudios generales sobre la nobleza en el conjunto de la Edad Media, entre ellos destacaremos el clásico de Isabel Beceiro

una buena visión comprensiva a través de SoRIA Mesa, La biblioteca genealógica de don Luis de Salazar y Castro.

4 No podemos hacer ahora una relación de todas las publicaciones de los autores que mencionaremos a continuación, lo que alargaría mucho estas páginas, pero sí citaremos algunas obras que consideramos de referencia. El lector interesado tendrá que acudir a los repertorios bibliográficos, donde encontrará sin dificultad muchas más referencias.

5 Destacaremos su "De la nobleza vieja a la nobleza nueva"; y también "La sociedad política castellana en la época de Alfonso XI".

6 La Tierra de Campos Occidental; y "La nobleza de León y Castilla en los siglos XI y XII".

Los señorios de los Montes de Torozos. De la repoblación al Becerro de las Behetrías (siglos X-XIV).

El conde Suero Vermúdez, su parentela y su entorno social.

La casa del rey en Castilla y León en la Edad Media.

10 Los señores de Vizcaya, siglos XI-XIV.

11 The aristocracy in twelfth-century León and Castile.

12 Los Lara. Un linaje castellano.

13 Los Lara. Nobleza y monarquía.

14 Grupos y dominios aristocráticos en la Tierra de Campos oriental.

15 "Los ricoshombres y el rey en Castilla: el linaje Haro (1076-1322)".

16 "Cum magnatibus regni mei".

17 Para otras zonas, también los trabajos de Eduardo Pardo de Guevara para la nobleza en Galicia o de Rafael Sánchez Saus en Andalucía: Pardo de Guevara, Los señores de Galicia.; Sánchez Saus, Caballería y linaje en la Sevilla medieval.

18 Linhagens medievais portuguesas.

19 Las behetrías castellanas; y véase también el primero de sus libros póstumos, Los territorios del rey. Castilla. Siglos XII-XIII. 
y Ricardo Córdoba ${ }^{20}$. Para el período posterior, la Baja Edad Media, los trabajos son mucho más numerosos.

Pero nuestro objetivo ahora no es reflexionar sobre la nobleza en la Plena Edad Media, sino sobre las fuentes disponibles para su estudio, específicamente en el período entre 1200 y 1350 aproximadamente. Algunos de los autores mencionados y otros han realizado reflexiones sobre las fuentes que han utilizado para estudiar tal o cual personaje o familia, o grupos de familias o personajes. Sin embargo, los análisis comprensivos sobre las fuentes disponibles para estudiar la nobleza en este período no son muy abundantes. En ese sentido destaca sobre todo el trabajo de Miguel Calleja-Puerta, que ha publicado varias e importantes contribuciones sobre ello ${ }^{21}$.

Como hemos señalado más arriba, no se han conservado archivos nobiliarios propiamente dichos para la Plena Edad Media; sin embargo, esa afirmación merece algunas matizaciones, porque en algunos casos sí contamos con algo bastante parecido. Algunos monasterios conservaron bloques de documentación importante sobre determinados nobles, generalmente sus fundadores o patronos. No solo documentos relativos a las fundaciones (a los que aludiremos de nuevo enseguida), sino otros documentos de esos nobles. Algunos de esos documentos se refieren a la trayectoria de los bienes que después por una u otra vía acabaron en manos de los monasterios; pero otros no guardan relación aparente ni con esos monasterios ni con sus bienes, y forman, por lo tanto, lo más parecido que tenemos en León y Castilla a archivos nobiliarios en este período. No son demasiados casos y son bastante bien conocidos, por lo que no es necesario detenerse mucho en ellos aquí. Nosotros hemos estudiado en ese sentido la importante documentación conservada en el monasterio de Santa María de Villamayor de los Montes sobre su fundador García Fernández de Villamayor y su familia ${ }^{22}$. Otros casos bien conocidos son los de los monasterios de Santa María de Otero de las Dueñas y Santa María de Carrizo, ambos en León. El primero conserva 93 documentos del conde Fruela Muñoz y su familia y otros 90 del conde Pedro Flaínez y la suya, ambos destacados personajes de la primera mitad del siglo $\mathrm{XI}^{23}$. El segundo, conserva también unos 130 documentos de Gonzalo Morán, merino mayor de León a mediados del siglo XIII, y su familia ${ }^{24}$.

\footnotetext{
20 No es el único, pero sí el que nos sigue pareciendo más importante: Parentesco, poder y mentalidad. También Gerbet, Las noblezas españolas en la Edad Media; o MenÉndez Pidal, La nobleza en España. 21 "Archivos dispersos, fuentes reencontradas"; "Les sources documentaires pour l'histoire des familles aristocratiques"; "El factor genealógico"; "Memoria escrita de la aristocracia en monasterios"; y "Señores sin cancillería".

22 Álvarez Borge, "Los dominios de un noble de la corte castellana en la primera mitad del siglo XIII". Y la documentación en Martínez Díez y González Sánchez, Monasterio cisterciense de Santa María de Villamayor.

23 García Leal, El archivo de los condes Fruela Muñoz y Pedro Flaínez, además de otros trabajos de este autor: "Los condes Fruela Muñoz y Pedro Falínez", y "El archivo de los condes Fruela Muñoz y Pedro Flaínez". En cuanto a los documentos, Fernández Flórez y Herrero de la Fuente, Colección documental del monasterio de Santa María de Otero.

24 Sobre Gonzalo Morán, véase Jular Pérez-Alfaro, Los adelantados y merinos mayores de León; y Gautier Dalché, "Noblesse, terre et argent". También sobre él y los documentos Casado Lobato, Colec-
} 
No es casualidad que los tres monasterios citados fueran de monjas cistercienses, puesto que son los monasterios cistercienses femeninos uno de los focos más importantes, si no el que más, de la documentación nobiliaria conservada en la Plena Edad Media. Además de estos casos, que son lo más parecido que podemos encontrar a archivos nobiliarios, la fundación de los monasterios femeninos cistercienses ( $\mathrm{y}$ antes algunos benedictinos) también dio lugar a que en esos archivos monásticos se conservaran un buen número de documentos nobiliarios referidos a la fundación y en algunos casos a la trayectoria anterior de los bienes que formaron la dotación fundacional. Son casos más numerosos y también son conocidos de manera que no nos detendremos en ellos ${ }^{25}$. Sirva, a modo de ejemplo, recordar que en el monasterio de Santa María de Herce, fundado a mediados del siglo XIII, se conservaron 20 documentos de sus fundadores, Alfonso López de Haro y su primera esposa María Álvarez y la segunda Sancha Gil; de ellos, ocho corresponden a donaciones al monasterio y el resto se refieren a la trayectoria anterior de los bienes donados o a otros $\operatorname{casos}^{26}$.

Fuera de esos bloques documentales, los textos para estudiar a la nobleza castellana en el período del que nos ocupamos (1200-1350, aproximadamente) están dispersos entre numerosos archivos y la tarea de reconstrucción genealógica y patrimonial se torna muchas veces muy complicada.

Con ese panorama general y en ese contexto historiográfico, nuestro propósito en las siguientes páginas es ofrecer una visión global y pretendemos que bastante detallada sobre la documentación conservada para estudiar un grupo familiar, los Rojas, a modo de ejemplo y para mostrar "las posibilidades y los límites de la documentación”, tomando prestada la expresión de Miguel Calleja ${ }^{27}$.

Como decimos, un primer problema y muy importante es la propia reconstrucción genealógica. Problema tanto mayor cuanto más nos alejemos de la alta nobleza. Por ello, antes de entrar en la descripción y el análisis de la documentación conservada sobre los Rojas, merece la pena mostrar brevemente la composición del grupo familiar de los Rojas. ¿Quiénes eran los Rojas?

ción diplomática del monasterio de Carrizo, esp. T. 1, pp. XXII-XXIII y XXIX-XXXI. Sobre los casos mencionados de los monasterios de Otero y de Carrizo y algunos otros, Calleja-Puerta, "Señores sin cancillería", pp. 23-24; o "Archivos dispersos", pp. 15-17.

25 Entre otros, véase Baury, Les religieuses de Castille; Alonso Álvarez, "Los promotores de la Orden del Císter"; o Cavero Domínguez, "El monasterio medieval, sede de solar nobiliario". Trabajos donde los lectores interesados podrán encontrar otras referencias bibliográficas. Sin embargo, todavía quedan monasterios por estudiar y fondos documentales por editar, y otros, publicados hace mucho tiempo, merecerían una revisión.

26 La fundación y los documentos en Pérez Carazo, Santa María de Herce, donde publica también la "Colección diplomática medieval de Santa María de Herce y su abadengo en la Edad Media" en formato CD.

27 "El factor genealógico". 


\section{Breve visión general del grupo familiar de los Rojas}

A lo largo de los años, hemos dedicado varios trabajos a estudiar a los Rojas desde que comienzan a documentarse hacia 1200 hasta mediados del siglo XIV ${ }^{28}$.

Los Rojas fueron un grupo familiar muy amplio cuyos miembros mayoritariamente se encuadran en los sectores de la media y baja nobleza castellana, aunque algunos de ellos protagonizaron un proceso de ascenso social a finales del siglo XIII y comienzos del XIV en el contexto de la crisis política de esos años ${ }^{29}$. Su solar originario, el lugar del que tomaron su apellido, era la villa de Rojas, al noreste de Burgos, en la Bureba, cerca de Briviesca. Tratándose de nobles que originariamente no pertenecen a la alta nobleza es muy difícil seguir su rastro antes de que comiencen a utilizar apellidos identificadores a finales del siglo XII y comienzos del siglo XIII. En nuestro caso, el primer documento en que los Rojas se documentan como tales es de 1192 y antes de eso es prácticamente imposible saber quiénes fueron sus antecesores ${ }^{30}$. A partir de ahí hemos podido reconstruir los integrantes de un amplio grupo familiar formado por unos 160 individuos en el período indicado, hasta mediados del siglo XIV.

Tres personajes de finales del siglo XII y comienzos del siglo XIII, Diego Díaz de Rojas, Alfonso Díaz de Rojas y Rodrigo Díaz de Rojas, a quienes consideramos hermanos (el segundo y el tercero lo eran con seguridad, y creemos que eran hermanos también de Teresa, García Díaz y Pedro Díaz) dan origen a otras tantas ramas, de las cuales podemos seguir el rastro a lo largo de las siguientes generaciones a los descendientes de los dos primeros mencionados: Diego Díaz de Rojas y Alfonso Díaz de Rojas ${ }^{31}$.

La rama de los descendientes de Diego Díaz de Rojas será la más poderosa. Tuvo cuatro hijos (quizás cinco); uno de ellos fue Fernán González de Rojas, merino mayor de Castilla a finales del reinado de Fernando III y en los primeros años del de Alfonso X. Otro fue Ruy Díaz, apodado el Gallego, padre, a su vez, de Juan Rodríguez de Rojas, también merino y adelantado mayor de Castilla entre 1293 y 1301 y que alcanzó la ricahombría. Un hijo suyo, Lope Díaz de Rojas, asimismo fue brevemente merino mayor de Castilla en 1332, también de Galicia en 1342 y 1343 y después de Guipúzcoa desde 1345 hasta, creemos, 1353. Lope Díaz fue un destacado señor a mediados del siglo XIV, según se recoge en el Becerro de las Behetrías ${ }^{32}$.

Pero, si la rama de Diego Díaz fue la más poderosa, la más numerosa fue la procedente de Alfonso Díaz, puesto que tuvo once hijos y de varios de ellos podemos reconstruir su sucesión a lo largo de varias generaciones. A esta rama pertenece, por ejemplo, Fernando Ladrón de Rojas, también merino mayor de Castilla en 1331 y 1332. En conjunto, como

\footnotetext{
28 Sobre todo, “Los señoríos de los Rojas en 1352"; también "Poder local y poder central”; y nuestro último trabajo sobre ellos, Ascenso social y crisis politica en Castilla.

29 Véase también EstePA, Las behetrías castellanas, T. 1, pp. 386-395.

30 Peña PÉrez, Documentación del monasterio de San Juan de Burgos, doc. 54.

31 Para las reconstrucciones genealógicas véanse los trabajos citados más arriba, especialmente los cuadros genealógicos en Ascenso social y crisis política.

32 Álvarez Borge, "Los señoríos de los Rojas".
} 
hemos dicho, documentamos unos 160 individuos en este período y podemos situar en su contexto familiar y patrimonial a unos 120 . De otros no conocemos exactamente sus lazos de parentesco, incluyendo algunos que también fueron personajes que alcanzaron un cierto relieve como Sancho Sánchez de Rojas, ballestero mayor en el reinado de Alfonso XI y comienzos del de Pedro I.

Para reconstruir la familia y la trayectoria de los Rojas son fundamentales los documentos. Las fuentes diplomáticas no son las únicas a las que debemos acudir (más adelante nos referiremos brevemente a las otras fuentes), pero sí son las más importantes.

\section{Los documentos. Número y tipos}

En las tablas que adjuntamos como apéndice pueden verse con detalle los datos sobre los documentos que se han conservado (y que nosotros conocemos) sobre los Rojas y que hemos agrupado en períodos entre 1176 y 1369. En total conocemos 582 documentos referidos a ellos en esos años. Es una cifra que puede parecer elevada, pero resulta un tanto engañosa. Para una valoración más precisa de la cantidad de los documentos y de la calidad de la información que proporcionan los hemos dividido en cuatro grupos. En absoluto se trata de una clasificación diplomática. Un estudio de ese tipo sería interesante, pero no es nuestro objetivo en estas páginas. Se trata de una clasificación puramente instrumental que intenta reflejar el volumen de la información y la utilidad de los documentos para el estudio histórico. Por ello, es una clasificación discutible; pero, siendo discutible, confiamos en que también sea útil.

Antes de avanzar en el análisis, conviene señalar que en nuestro recuento hemos incluido solo los documentos que se refieren a los Rojas directamente; es decir, aquellos en los que consta expresamente la participación de uno o varios Rojas identificados mediante su apellido toponímico o también algunos otros (pocos) documentos en los que, aunque no figure el apellido Rojas, por unas u otras razones, no nos cabe ninguna duda de que se trata de los Rojas. La casuística es compleja y diversa y no podemos explicar ahora cada caso, pero los documentos en los que cabe alguna duda razonable sobre la identidad de los personajes los hemos excluido del recuento. Por otro lado, tampoco hemos incluido documentos referidos a otros nobles no Rojas, pero estrechamente relacionados con ellos y que indirectamente nos ayudan a situar social o políticamente a los Rojas: parientes políticos (suegros, cuñados...), aliados, señores, etc. En el estudio histórico esos documentos sobre esos otros personajes han de tenerse presentes y en algunas ocasiones pueden llegar a ser claves para situar correctamente a tal o cual individuo de los Rojas, pero no los hemos incluido en el recuento porque, siendo los Rojas un grupo familiar tan amplio, el círculo podría alargarse enormemente.

Como hemos indicado, la cifra total de 582 documentos es un tanto engañosa sobre el volumen de la información disponible, pero sí es bien expresiva de la cantidad de fuentes que ha sido necesario consultar, como veremos más adelante. 
Hemos dividido el conjunto de documentos conservados (y, es necesario insistir, conocidos) en cuatro grupos. Los documentos que hemos llamado " $\mathrm{A}$ " son los documentos más informativos. Son los documentos clave que permiten reconstruir el grupo familiar. Son textos de diverso tipo, pero que ofrecen la información más rica sobre relaciones de parentesco y/o sobre bienes patrimoniales. Lógicamente no podemos citarlos todos aquí, pero entre ellos hay que tener en cuenta el acuerdo que alcanzaron en 1217 un buen número de Rojas con los habitantes de Hontomín (una pequeña villa situada a unos $25 \mathrm{~km}$ al norte de Burgos). En Hontomín, que pertenecía al monasterio de Oña, había muerto Diego Rodríguez, hijo de Rodrigo Díaz de Rojas, y ahora sus "fratres et consanguinei atque parentes" se comprometen a no tomar venganza por su muerte a cambio de ciertas condiciones. En ese acuerdo participaron 17 individuos, 15 hombres y dos mujeres. Muy poco después, otro documento, ahora de 1223, recoge dos "entramientos" de heredades pertenecientes al monasterio de la Trinidad de Burgos, uno de ellos protagonizado por otro Rojas. Para su resolución hubo varias reuniones ("conceios", los denomina el documento) en que participaron también varios Rojas; algunos de ellos coincidentes con los mencionados en el documento de Hontomín y otros no ${ }^{33}$. A partir de estos y otros documentos se puede empezar a ir reconstruyendo el grupo familiar desde que sus integrantes comienzan a utilizar el apellido.

Los documentos tipo "B" son documentos también protagonizados por Rojas, pero, diríamos, con información "normal" sobre parentesco y propiedades. Por ejemplo, "X" y su mujer, quizás con alguno de sus hijos, compran, venden o donan bienes en un lugar o en un pequeño número de lugares. También textos que incluyan a algún Rojas como fiador de otro, sea ese otro miembro también del grupo familiar o no. O también documentos que recojan actuaciones de oficiales regios (pesquisas, sentencias, etc.)

Entre los documentos tipo " $C$ " hemos agrupado a aquellos que también dan información directa sobre los Rojas, pero menos rica. Pueden ser, por ejemplo, casos en los que algún Rojas (siempre bien identificado como tal) figura como testigo en algún documento que recoge un negocio jurídico protagonizado por otros. O también documentos en los que se mencionan propiedades de algún Rojas entre las que limitan con otras que son vendidas o donadas por otros. A veces estas informaciones pueden ser muy esclarecedoras (un Rojas testigo en un documento de un magnate, por ejemplo), pero como criterio general, para no hacer demasiadas excepciones, hemos incluido todos estos documentos en el grupo "C".

Y, por último, los documentos tipo " $D$ " son aquellos que ofrecen referencias secundarias, documentos que, generalmente, no aportan información nueva, sino que corroboran otra. Aquí también la casuística es variada; por ejemplo, confirmaciones o acuerdos sobre negocios jurídicos realizados con anterioridad; aunque el bloque más numeroso vendrá dado por los documentos en los que figura la referencia a tal o cual oficial regio, como los merinos mayores en los privilegios regios o en los escatocolos de documentos pri-

\footnotetext{
33 Sobre estos documentos y su interés en el estudio de los primeros Rojas documentados, Álvarez Borge, Ascenso social y crisis política, pp. 37-42.
} 
vados; también mandatos de tipo genérico de los reyes a sus oficiales. A veces también pueden ser esclarecedores y permitirán confirmar o precisar períodos de ocupación de oficios públicos, pero en su gran mayoría ofrecen información repetitiva.

Las Tablas 1 y 2 recogen los datos de cada tipo de documentos:

- 19 de tipo "A", el 3,26\%;

- 177 del tipo "B", el 30,41\%;

- 90 del tipo "C", el 15,46\% y

- 296 del "D", el 50,85\%.

En la Tabla 1 vemos también la distribución en el tiempo de los distintos tipos de documentos. Hemos dividido el período que estudiamos en ocho bloques de 25 años, aunque el primero de 1176 a 1200 está muy desequilibrado, puesto que solo se conservan dos documentos; uno es el mencionado de 1192 y otro de 1199; ambos son documentos tipo "C". Por otro lado, el último bloque alcanza solo hasta 1369 (no hasta 1375, como correspondería mecánicamente), porque nos ha parecido más conveniente cerrar el estudio con la muerte de Pedro I y el cambio de dinastía. Lógicamente los documentos tienden a hacerse más numerosos a medida que pasan los años, aunque el mayor volumen no se da al final, sino en el período 1301-1325; por un lado, claramente, por los documentos "D", los privilegios regios que recogen a Juan Rodríguez de Rojas como confirmante en su calidad de ricohombre; pero llama la atención el elevado número de documentos tipo "B" también en ese período, 53 sobre un total de 177, el 32\%. Fuera de eso y dejando de lado el primer bloque, los documentos se reparten de forma relativamente consistente en todos los períodos, con la excepción de que no hay ningún documento tipo "A" en los últimos años, ninguno tipo "C" entre 1251 y 1275, ni tipo "D" entre 1201 y 1225. Las cifras de la columna " $D$ " son las menos representativas por las referencias a los Rojas que fueron oficiales regios. Esas serían las características más notables por lo que se refiere a la distribución temporal de los documentos.

No podemos hacer ahora un estudio detallado del contenido de los documentos (más allá de la clasificación que proponemos), pero sí pensamos que merece la pena algún comentario breve. En la Tabla 3 clasificamos los documentos "A" y "B" según su contenido formal ${ }^{34}$. Ignoramos ahora los documentos " $\mathrm{C}$ " y " $\mathrm{D}$ " porque son los que menos información proporcionan y porque en muchos casos los actores que los protagonizan no son Rojas. La suma de los documentos "A" y "B" es de 196 documentos. De ellos, destacan por su mayor número las ventas, las donaciones realizadas y los documentos que hemos incluido en la columna "otros"; en ella hay documentos de diverso tipo, por ejemplo, algunos testamentos, pero el mayor número corresponde a documentos que reflejan actuaciones de los Rojas que fueron merinos mayores (pesquisas, sentencias).

\footnotetext{
34 Es una clasificación atendiendo al contenido formal. Hay ventas que en realidad son empeños, donaciones que responden a pleitos previos, etc. Un análisis pormenorizado requeriría el estudio de una casuística individualizada. Aún así, teniendo en cuenta que se trata de una clasificación formal, consideramos significativas las conclusiones que pueden obtenerse.
} 
Es llamativo el número de ventas que se concentran sobre todo en dos momentos, en los años centrales del siglo XIII y en las primeras décadas del siglo XIV. Las primeras en relación con procesos de formación y/o reorganización de algunos dominios eclesiásticos (el hospital del Rey, el monasterio de Las Huelgas, la catedral de Burgos); las segundas, de mayor volumen en muchos casos, quizás en relación con la crisis e inestabilidad política de esos años. Son los mismos períodos en que se acentúa la política de compras y seguramente por las mismas razones. También los pleitos en que se vieron envueltos los Rojas son más numerosos a comienzos del siglo XIV y también han de relacionarse con las situaciones de inestabilidad. Las donaciones recibidas no son muy numerosas: algunas donaciones regias y otras concesiones de instituciones eclesiásticas que buscaban protección de los Rojas por unos u otros motivos. Son más numerosas las donaciones realizadas, que hay que poner en relación con la política de los Rojas hacia algunos monasterios con los que tuvieron una relación más estrecha y en los que eligieron enterramiento; sobre todo con el monasterio de Vileña.

La mayor parte de los documentos que conocemos han sido publicados (Tabla 2). Sobre el total de 582, son 509 los editados frente a 73 los inéditos, aunque la cifra de estos últimos es apreciable (el 12,54\%). Merece la pena alguna explicación adicional a los datos, porque hemos contado como inéditos aquellos que se conocen solo por regestos siendo el caso que existen documentos completos. Sería el caso, por ejemplo, de los documentos de la catedral de Burgos entre 1223 y 1253, inéditos porque la serie de la colección diplomática está incompleta, pero conocidos parcialmente gracias los catálogos publicados. También consideramos inéditos los documentos conocidos solo por las copias de la Colección Salazar y Castro; mientras que los procedentes de esa colección que han sido después publicados en colecciones diplomáticas diversas los hemos incluido entre los editados.

Dejando de lado los documentos tipo " $\mathrm{D}$ ", que son los menos representativos, los porcentajes de editados e inéditos de los otros tipos de documentos también son bastante consistentes: entre el 77 y el $84 \%$ de documentos editados y entre el 15 y el $22 \%$ de inéditos.

La procedencia de los documentos, tanto editados como inéditos, también merece un análisis detallado.

\section{Procedencia de los documentos}

Si no hay nada parecido a un archivo de los Rojas en estos momentos (entre otras cosas porque, dadas sus diversas ramas, habría que pensar en varios archivos de los Rojas) ¿dónde está la documentación para poder estudiarlos? ¿De dónde proceden los documentos? En la Tabla 4 ofrecemos los datos globales por tipos de documentos (A, B, C y D) y en las Tablas 5 a 10 los datos distribuidos según tipos de fondos.

También es necesaria alguna consideración previa sobre el método que hemos seguido. Nos interesa estudiar la procedencia de los documentos, no la obra donde se hayan editado, por eso hemos intentado reflejar el origen de los documentos en la medida 
de lo posible. Por otro lado, en los casos en que un documento se haya publicado en más de una colección diplomática, lo incluimos en el lugar al que nos parece está más relacionado (por ejemplo, los documentos del monasterio de Las Huelgas y del hospital del Rey de Burgos publicados en ambas colecciones diplomáticas).

No son pocos los casos de documentos procedentes de instituciones que están parcialmente publicados y parcialmente permanecen inéditos (la catedral de Burgos, el hospital del Rey, el monasterio de Aguilar, el de San Millán de la Cogolla, etc.). En esos casos, en la Tabla 4 hemos incluido entradas distintas para los publicados y los inéditos según su procedencia (por ejemplo, en el caso del hospital del Rey hay documentos publicados y entre los inéditos la mayoría proceden del Archivo del Palacio Real, pero también hay alguno de la Biblioteca Zabálburu). El objetivo es mostrar con el mayor detalle posible la dispersión y las dificultades para acceder a los documentos; pero también tiene sentido reflejar el archivo originario de los documentos, al margen de su dispersión posterior (Tablas 5 a 10).

De esa forma, en la Tabla 4 ofrecemos un total de 106 entradas, que corresponden a las colecciones diplomáticas y los archivos (para el caso de los documentos inéditos) donde se han conservado documentos de los Rojas. Una cifra, evidentemente, muy alta. Unificando los documentos editados e inéditos por instituciones y archivos la cifra se reduce un poco, pero sigue siendo muy alta. Con ese criterio, el número de entradas es de 93, que se distribuyen de la siguiente manera:

- 13 archivos nobiliarios y otros archivos aportan de 31 documentos, el 5,32\% del total

- 7 catedrales, aportan 61 documentos, el 10,48\%

- 23 concejos, aportan 68 documentos, el 11,68\%

- 41 monasterios, aportan 313 documentos, el 53,78\%

- 4 órdenes militares, aportan 19 documentos, el 3,26\% y

- 5 colecciones regias, aportan 90 documentos, el 15,46\%

La mayor abundancia de documentos procedentes de monasterios es perfectamente lógica, pero para ser realmente expresivas, esas cifras necesitan un análisis más detallado. El número elevado de documentos procedentes de colecciones regias (Tabla 10) obedece a un criterio contable que no deja de ser discutible. Entre esos documentos hay algunas, muy pocas, donaciones regias a varios Rojas y algunas confirmaciones, pero la mayoría corresponden a la presencia de oficiales regios (merinos mayores casi siempre) en los privilegios regios y también a algunos mandatos regios genéricos dirigidos a esos oficiales. Son casi siempre documentos tipo " $D$ " y hemos optado por contabilizarlos de manera conjunta para no distorsionar las cifras y porque fueron documentos expedidos por las cancillerías regias.

También son en su mayoría documentos tipo "D" los documentos de los concejos (Tabla 7), aunque entre ellos hay más diversidad. Muchos corresponden también a la actuación 
de oficiales regios y destaca el número de concejos guipuzcoanos en relación con el oficio de merino mayor de Guipúzcoa de Lope Díaz de Rojas a mediados del siglo XIV. Entre los archivos diocesanos (Tabla 6), episcopales y capitulares, hemos contabilizado también una iglesia parroquial, la de San Juan de Oña, cuya documentación se conoce gracias al trabajo de Francisco Ruiz Gómez y que constituye un fondo muy importante, no solo por la cantidad de documentos (16) sino también por su calidad, puesto que 4 de los 19 documentos que consideramos más importantes, los documentos tipo "A", proceden de ese fondo ${ }^{35}$. Fuera de ese caso, es, lógicamente, la catedral de Burgos la que más documentos aporta, junto a las sedes riojanas de La Calzada y Calahorra. Y destaca también la presencia en el listado de la catedral de Murcia, que aporta tres documentos, por la proyección murciana de algunos Rojas en la primera mitad del siglo XIV (Sancho Ruiz de Rojas y su familia).

Por lo que se refiere a las órdenes militares, hay documentos sobre los Rojas entre los fondos de las de Calatrava, Alcántara, San Juan y Santiago (Tabla 9); pero es la primera de ellas, la orden de Calatrava, la que mantuvo una relación más estrecha con los Rojas, pues de ella proceden más de la mitad de los documentos. Importa también señalar que entre los 19 documentos procedentes de órdenes militares hay dos de los documentos más importantes, del tipo " $\mathrm{A}$ ", y otros cuatro del tipo "B".

Pero son los monasterios (entre los que hemos contabilizado también al hospital del Rey de Burgos) los que nos proporcionan el mayor número de documentos. Nominalmente son 313 , el $53,78 \%$ del total y proceden de 41 instituciones diferentes (Tabla 8). Destacan los monasterios castellanos y, sobre todo, los de las zonas donde los dominios de los Rojas eran más intensos (Burgos, Palencia), pero hay también monasterios leoneses, cuya presencia en las tablas se explica sobre todo por las referencias a algunos Rojas en las cláusulas de datación en tanto que oficiales públicos; y son llamativos también los documentos sobre los Rojas en los monasterios gallegos, que se explica por su proyección como merinos en Galicia. Pero el grueso de los documentos monásticos se concentra en unos pocos centros. De los 41 monasterios, siete aportan 10 o más documentos (12 son los que aportan ocho o más) y, en realidad, casi la mitad de todos los documentos procedentes de monasterios se concentra en tres fondos, los de los monasterios de las Huelgas de Burgos, San Salvador de Oña y Santa María de Vileña. Entre los tres suman 151 de los 313 documentos de monasterios y de los 582 documentos totales; esto es, el 48,24\% de los documentos monásticos o el 25,94\% del total. Podemos tener una visión más precisa si atendemos también al tipo de documentos. En la lista de los primeros monasterios de la Tabla 8 podemos eliminar aquellos que proporcionan solo documentos tipo "D", esto es, los monasterios de Sahagún (15 documentos) y Santo Toribio de Liébana (9). Si valoramos los monasterios que aportan más documentos tipo "A" hemos de poner en valor la importancia de los fondos del monasterio de la Trinidad de Burgos (tres documentos tipo "A"). De esa manera a los monasterios ya citados de Las Huelgas, Oña y Vileña hemos de añadir el hospital del Rey y el monasterio de la

35 Ruiz Gómez, “Apéndice I”, en Las formas de poblamiento rural en la Bureba, T. 2, pp. 845-1309. 
Trinidad, ambos en Burgos. Si a ellos les sumamos la Catedral de Burgos y la Iglesia de San Juan de Oña, tendríamos el bloque fundamental de la documentación eclesiástica sobre los Rojas, un bloque que, en su mayoría, aunque no todo, está publicado ${ }^{36}$.

Faltaría otro bloque importante de documentación en buena medida inédita, la procedente de los archivos nobiliarios, que hemos recogido en la Tabla 5, junto a la de otros archivos y fondos.

En la Tabla 5 hemos recogido esos datos, que incluyen documentos procedentes del Archivo de la Corona de Aragón, de la Sección Cámara de Castilla del Histórico Nacional, de Simancas y de la Chancillería de Valladolid. Algunos están publicados en colecciones diplomáticas (Don Juan Manuel o Diego López de Haro $\mathrm{V}^{37}$ ) y otros inéditos los hemos localizado mediante búsquedas a través Pares o de otros repositorios como Badator para los documentos del País Vasco ${ }^{38}$. La Colección Salazar y Castro ha aportado un número significativo de documentos procedentes de archivos nobiliarios inéditos ${ }^{39}$. Cuando Salazar o sus copistas indicaron la procedencia de los textos los hemos incluido en su lugar correspondiente (por ejemplo, Archivo de los condes de Villaverde), pero de algunos de ellos no indicaron la procedencia, por lo que los hemos recogido en una entrada específica. Y lo mismo cabe decir para los documentos publicados en las Pruebas de la Casa de Lara, muchas veces se indica la procedencia, pero otras no ${ }^{40}$.

Además de esos textos, hemos encontrado documentos sobre los Rojas en otros siete archivos nobiliarios, la mayoría de los cuales se encuentran hoy en el Archivo Histórico de la Nobleza en Toledo, aunque no todos: el archivo de los duques de Osuna (Infantado), el de los duques de Frías y los de los marqueses de Agoncillo y Poza. Allí se custodia también el archivo de los condes de Villaverde (ahora condes de Villaverde de Madrid), aunque hemos accedido a los documentos procedentes de ese archivo a través de la Colección Salazar y Castro o de otras colecciones diplomáticas. Y fuera del Archivo Histórico de la Nobleza, hemos encontrado documentos sobre los Rojas que están o han estado en los archivos de los duques de Medinaceli y de los duques de Nájera, en el primero a través también de la Colección Salazar y Castro y en el segundo por su publicación en las Pruebas de la Casa de Lara ${ }^{41}$. Merece la pena subrayar que, aunque el número de los documentos de estos fondos es relativamente bajo (31 documentos en

\footnotetext{
36 Estas siete instituciones aportan en conjunto 216 documentos, que suponen el $37,11 \%$ del total. Si excluimos los documentos tipo "D" tenemos una visión algo más enfocada; con ese criterio, estas instituciones aportan 158 documentos sobre el total de 286 documentos de los tipos "A", "B" y "C", esto es el 55,24\%. Buscando solo los documentos tipo "A", aportan 14 de los 19, esto es, el 73,68\%.

37 Giménez Soler, Don Juan Manuel; Lucas de la Fuente, D. Diego López de Haro V.

38 Badator, el visor de documentos on-line del Servicio de Archivos y Patrimonio Documental del País Vasco (Artxibo), en https://dokuklik.euskadi.eus/. Pares (Portal de Archivos Españoles) en http://pares. mcu.es/.

39 El catálogo fue publicado en 49 vols. por Cuartero Huerta y VArgas-Zúñiga, Indice de la Colección de Don Luis Salazar y Castro; ahora puede consultarse en formato pdf en la página web de la Academia de la Historia (https://www.rah.es/wp-content/uploads/2016/11/SalazaryCastro_22_nov_2016.pdf)

40 Salazar y Castro, Historia genealógica de la Casa de Lara, vol. IV, Pruébas de la historia de la Casa de Lara.

41 Véase el detalle de la procedencia de esos documentos en la Tabla 4.
} 
total), sin embargo, su calidad no lo es. Son dos documentos tipo "A" y otros 16 tipo "B". Aunque también es cierto que prácticamente todos los documentos procedentes de estos fondos son del siglo XIV.

\section{Otras fuentes para estudiar los Rojas}

En este artículo nos hemos centrado en las fuentes diplomáticas (compraventas, donaciones, pleitos...) que, en efecto, son las más importantes y las que nos ofrecen mayor volumen de información para estudiar a los Rojas en el período considerado, pero no son las únicas. Las repasaremos también ahora, aunque de una forma mucho más breve. En primer lugar, hay que mencionar también a las crónicas. Por lo que se refiere a información directa sobre los Rojas (no a información referida a otros personajes relacionados con los Rojas, caso en el que las noticias son más abundantes), hemos encontrado referencias en la Primera Crónica General y en las crónicas de Sancho IV, Fernando IV, Alfonso XI, y Pedro I y Enrique II, y también en los Anales de la Corona de Aragón de Zurita. No en la de Alfonso X o en otras como la de Jofré de Loaysa, la Crónica latina o la de Jiménez de Rada. La información sobre los Rojas en las crónicas es relativamente abundante y nos ofrece datos, claro está, sobre todo en relación con su actividad política, también circunstancialmente algunos datos sobre relaciones de parentesco y otras informaciones diversas, como por ejemplo, el dato clave de que Juan Rodríguez de Rojas fue ricohombre a finales del siglo XIII y comienzos del XIV, elemento muy importante para conocer su trayectoria y su posición, así como la de otros parientes próximos de esa rama de los Rojas ${ }^{42}$.

También algunas fuentes descriptivas nos ofrecen información sobre los Rojas. En primer lugar, los repartimientos. Aunque las referencias son escasas, permiten saber que algunos Rojas (Diego Alfonso de Rojas y su hijo Alfonso Díaz) obtuvieron donadíos en el repartimiento de Sevilla, otros en el de Jerez o que otros tuvieron propiedades en Córdoba ${ }^{43}$.

Los libros de cuentas que se han conservado para el reinado de Sancho IV también ofrecen alguna información sobre algunos Rojas, como los situados de Juan Rodríguez de Rojas y de otros Rojas en los tributos de los judíos de varias juderías en 1291; o los cobros de soldadas en 1294 u otras informaciones circunstanciales (como que Juan Rodríguez de Rojas era señor de Santa María de Ribarredonda) a partir de otros

\footnotetext{
42 Para no alargar las notas excesivamente, a menos que nos refiramos a alguna noticia concreta, no señalaremos las ediciones de las crónicas (como tampoco hemos hecho con las colecciones diplomáticas), que son fácilmente localizables en los repertorios. En cuanto a la referencia a Juan Rodríguez de Rojas como ricohombre, Crónica de Alfonso XI, ed. Rosell en Crónicas de los Reyes de Castilla, pp. 353-354. 43 González González, Repartimiento de Sevilla, T. 2, p. 234; GonzÁlez Jiménez y GonzÁlez Gómez, Repartimiento de Jerez, pp. 45-47 y 139; y Nieto Cumplido, "El libro del diezmo de los donadíos de la catedral de Córdoba", p. 162.
} 
fragmentos de cuentas ${ }^{44}$. Y el Libro de cuentas de los monasterios benedictinos de la provincia de Toledo de 1338 también ofrece algunas referencias sobre algunos Rojas ${ }^{45}$. Pero, sin duda, es el Becerro de las Behetrías la principal fuente de información sobre los Rojas, como sobre tantas otras familias de la nobleza castellana, además de las fuentes documentales. A su estudio hemos dedicado un trabajo específico, al que remitimos al lector interesado para una visión detallada ${ }^{46}$.

\section{Conclusiones}

Nos parece necesario subrayar la idea de la enorme dispersión de las fuentes documentales a las que debemos acudir para estudiar a los Rojas en este período. Así formulada no sorprenderá a los especialistas, pero ahora podemos poner cifras a esa dispersión: 106 colecciones diplomáticas y archivos, que corresponderían originariamente a 93 fondos documentales. Se trata de cifras muy elevadas.

En conjunto, los 582 documentos que a día de hoy conocemos para estudiar los Rojas entre 1200 y 1369 no son un número pequeño; no podemos decir que el volumen de las fuentes diplomáticas disponibles sea reducido. Aunque, si tenemos en cuenta que los Rojas eran un grupo familiar muy amplio, proporcionalmente el número de documentos conocidos resulta menor. Sin embargo, para acceder a esos textos es necesario consultar, literalmente, miles de documentos. Claramente algunos fondos aportan el mayor volumen de referencias. En nuestro caso, los principales monasterios de la Bureba (la zona originaria de los Rojas) y de la ciudad de Burgos, así como la catedral. Sin embargo, el ámbito de la proyección patrimonial y política de los Rojas (de unos u otros) era mucho mayor; en realidad, abarcaba prácticamente todo el reino. Sus propiedades y señoríos se extendían también por otras zonas de Burgos y de Palencia, pero también por Toledo, Murcia o Andalucía y la acción política de algunos Rojas alcanzó también el País Vasco y Galicia. De forma que hay que ampliar mucho el foco. De esa manera, podemos encontrar documentos referentes a los Rojas en lugares inesperados y en ocasiones esos documentos pueden llegar a ser muy importantes y esclarecedores de relaciones de parentesco, de la proyección patrimonial o de la posición social y política. Por consiguiente, el estudio es muy complicado, no por dificultades de tipo teórico o metodológico, sino por que es necesario mucho tiempo para revisar toda la documentación posible. Por otro lado, en la medida en que no hay un bloque más o menos cerrado de documentos, el estudio avanza a base de hipótesis y conclusiones parciales que en no pocas ocasiones es necesario ir revisando. De manera que difícilmente puede darse

\footnotetext{
44 Hernández Sánchez, Las rentas del rey, T. 1, pp. 143, 151 y 157; y López Dapena, Cuentas y gastos (1292-1294) del rey don Sancho IV, pp. 418, 435, 484, 517 y 626.

45 García GonzÁlez, "Libro de las cuentas de los monasterios benedictinos de la Provincia de Toledo de 1338", en Vida económica de los monasterios, esp. pp. 232 y 262.

46 Álvarez Borge, "Los señoríos de los Rojas en 1352"; y Estepa, Las behetrías castellanas, T. 1, pp. 386-395.
} 
por cerrado. A día de hoy no excluimos que algunas de nuestras propuestas sobre las relaciones de parentesco que hemos publicado en varios trabajos deban ser revisadas más adelante, seguramente no en los personajes de las líneas principales, pero sí en algunos de los de las ramas secundarias. De manera similar, los elementos todavía desconocidos quizás podrán esclarecerse en el futuro. En realidad, un estudio de este tipo no podrá darse nunca por definitivamente concluido. Lo único que cabe es pensar que razonablemente se ha alcanzado un nivel apreciable de conocimiento a partir de un volumen de documentos que se considere significativo.

Es bien posible que la consulta de nuevos fondos o una nueva revisión de los ya conocidos permita en el futuro aumentar el número de documentos conocidos sobre los Rojas en este período. Eso será más probable en lo que se refiere a los fondos procedentes de archivos privados. Pero es una tarea inabarcable para un único investigador. En todo caso, a medida que se vayan incorporando nuevos documentos al sistema Pares, podrá completarse poco a poco la información procedente de archivos nobiliarios. Por otro lado, hay que tener en cuenta que, a partir de lo que ya conocemos, hay pensar que los documentos anteriores a mediados del siglo XIV no serán muy abundantes y los del siglo XIII serán muy escasos. No pretendemos proponer que el estudio que hemos realizado sobre los documentos para estudiar a los Rojas en este período sea un modelo que pueda aplicarse mecánicamente a otros grupos familiares, pero sí creemos que es un buen ejemplo. Probablemente el elemento diferencial más notable sea la amplitud del grupo familiar, el elevado número de individuos que lo formaban en sus diversas ramas. Pero, fuera de eso, los Rojas no eran muy distintos a otros grupos familiares de la nobleza regional castellana: Velasco, Carrillo, Sandoval, etc. Su estudio, por muy complicado que sea por las dificultades de conocimiento y acceso a la documentación, es necesario para conocer la nobleza castellana en la Plena Edad Media.

\section{Bibliografía}

Alonso Álvarez, Raquel, "Los promotores de la Orden del Císter en los reinos de Castilla y León: familias aristocráticas y damas nobles", Anuario de Estudios Medievales, 37/2 (2007), pp. 653-710.

Álvarez Borge, Ignacio, "Los señoríos de los Rojas en 1352”, Los señoríos de behetría, Carlos Estepa y Cristina Jular (eds.), CSIC, Madrid, 2001, 73-144.

Álvarez Borge, Ignacio, "Los dominios de un noble de la corte castellana en la primera mitad del siglo XIII. García Fernández de Villamayor”, Hispania, LXVIII-230 (2008), pp. 647-706.

Álvarez Borge, Ignacio, "Poder local y poder central. Servicio al rey y desarrollo patrimonial en Castilla en el siglo XIII. El merino Fernán González de Rojas y sus descendientes", Edad Media. Revista de Historia, 18 (2017), pp. 146-176. 
Álvarez Borge, Ignacio, Ascenso social y crisis política en Castilla c. 1300. En torno a Juan Rodríguez de Rojas y su grupo familiar, Universidad de Salamanca, Salamanca, 2019. Argote de Molina, Gonzalo, Nobleza de Andalucía, Riquelme y Vargas Ediciones, Jaén, 1991 (ed. facsímil)

Barón Faraldo, Andrés, Grupos y dominios aristocráticos en la Tierra de Campos oriental, Diputación Provincial de Palencia, Palencia, 2006.

BARTOn, Simon, The aristocracy in twelfth-century León and Castile, Cambridge University Press, Cambridge, 1997.

BAURY, Ghislain, "Los ricoshombres y el rey en Castilla: el linaje Haro (1076-1322)", Territorio, Sociedad y Poder, 6 (2011), pp. 53-72.

BAURY, Ghislain, Les religieuses de Castille. Patronage aristocratique et ordre cistercien XII ${ }^{\mathrm{e}}$-XIII ${ }^{\mathrm{e}}$ siècles, Presses Universitaires de Rennes, Rennes, 2012.

Beceiro Pita, Isabel y Córdoba de la Llave, Ricardo, Parentesco, poder y mentalidad. La nobleza castellana siglos XII-XV, CSIC, Madrid, 1990.

CALDERón Medina, Inés, "Cum magnatibus regni mei”. La nobleza y la monarquía leonesas durante los reinados de Fernando II y Alfonso IX (1157-1230), CSIC, Madrid, 2011. CALderón Medina, Inés, Los Soverosa. Una parentela nobiliaria entre tres reinos. Poder y parentesco en la Edad Media hispana (siglos XI-XIII), Universidad de Valladolid, Valladolid, 2018.

Calleja-Puerta, Miguel, El conde Suero Vermúdez, su parentela y su entorno social. La aristocracia asturleonesa en los siglos XI y XII, KRL Ediciones, Oviedo, 2001.

Calleja-Puerta, Miguel, "Archivos dispersos, fuentes reencontradas: notas metodológicas al estudio de las élites del reino de León en los siglos centrales de la Edad Media", Medievalismo. Boletín de la Sociedad Española de Estudios Medievales, 12 (2002) pp. 9-36.

CAlleja-Puerta, Miguel, "Les sources documentaires pour l'histoire des familles aristocratiques du royaume de León ( $\mathrm{X}^{\mathrm{e}}-\mathrm{XII}{ }^{\mathrm{e}}$ siècle): production, usage et conservation", Le médiéviste et la monographie familiale: sources, méthodes et problématiques, Martin Aurell (ed.), Brepols, Turnhout, 2004, pp. 105-116.

CAlleja-Puerta, Miguel, "El factor genealógico: posibilidades y límites de la documentación de archivo para la elaboración de historias familiares", Emblemata. Revista Aragonesa de Emblemática, 16 (2010) pp. 123-153.

CAlleja-Puerta, Miguel, "Memoria escrita de la aristocracia en monasterios hispánicos de la edad románica", Monasterios y nobles en la España del románico. Entre la devoción y la estrategia, Fundación Santa María la Real, Aguilar de Campoo, 2014, pp. 205- 229.

Calleja-Puerta, Miguel, "Señores sin cancillería. Génesis y validación de los documentos de la aristocracia castellano-leonesa (1100-1250 ca.)", Escritura y sociedad. La nobleza, Ana Suárez González (ed.), Junta de Galicia y Universidad de Santiago de Compostela, Santiago de Compostela, 2017, pp. 19-58. 
Casado Lobato, María Concepción, Colección diplomática del monasterio de Carrizo, Centro de Estudios e Investigación San Isidoro, León, 1983, 2 vols.

Cavero Domínguez, Gregoria, "El monasterio medieval, sede de solar nobiliario y refugio de mujeres de la aristocracia", Monasterios y nobles en la España del románico. Entre la devoción y la estrategia, Fundación Santa María la Real, Aguilar de Campoo, 2014, pp. 97-135.

Cuartero Huerta, Baltasar y Vargas-ZúÑIga, Antonio, Indice de la Colección de Don Luis Salazar y Castro, Real Academia de la Historia, Madrid, 1949-1979, 49 vols.

Dacosta Martínez, Arsenio, "A propósito de un aparente silencio: la memoria genealógica escrita de la nobleza peninsular en la baja Edad Media", Tiempos Modernos, 32 (2016/1), pp. 73-87.

Dacosta Martínez, Arsenio, "La memoria de los antepasados: los relatos nobiliarios de origen en la península ibérica", Discurso memoria y representación. La nobleza peninsular en la Baja Edad Media, XLII Semana de Estudios Medievales de Estella, Gobierno de Navarra Pamplona, 2016, pp. 283-314.

Díaz Martín, Luis Vicente, Colección documental de Pedro I de Castilla (1350-1369), Junta de Castilla y León, Valladolid, 1997-1999, 4 vols.

Doubleday, Simon, Los Lara. Nobleza y monarquía en la España medieval, Turner, Madrid, 2004.

Estepa Díez, Carlos, Las behetrías castellanas, Junta de Castilla y León, Valladolid, 2003, 2 vols.

Estepa Díez, Carlos, Los territorios del rey. Castilla. Siglos XII-XIII, Madrid, Marcial Pons, 2021.

Fernández FlóReZ, José Antonio y Herrero de la Fuente, Marta, Colección documental del monasterio de Santa María de Otero de las Dueñas, Centro de Estudios e Investigación San Isidoro, León, 1999-2005, 2 vols.

Gaibrois, Mercedes, Historia del reinado de Sancho IV de Castilla, Tip. De la Revista de Archivos, Bibliotecas y Museos, Madrid,1922-1928, 3 vols.

García González, Juan José, "Libro de las cuentas de los monasterios benedictinos de la Provincia de Toledo de 1338", Vida económica de los monasterios benedictinos en el siglo XIV, Universidad de Valladolid, Valladolid, 1972.

García Leal, Alfonso, El archivo de los condes Fruela Muñoz y Pedro Flaínez. La formación de un patrimonio nobiliario en la montaña asturleonesa (854-1048), Universidad de León, León, 2010.

García Leal, Alfonso, "El archivo de los condes Fruela Muñoz y Pedro Flaínez (8541048): una visión nueva de viejos documentos", Signo. Revista de Historia de la Cultura Escrita, 13 (2004), pp. 121-147.

García Leal, Alfonso, "Los condes Fruela Muñoz y Pedro Falínez: la formación de un patrimonio señorial”, Anuario de Estudios Medievales, 36/1 (2006), pp. 1-110. 
García Luján, José Antonio, Judios de Castilla (siglos XIV-XV). Documentos del Archivo de los Duques de Frías, Universidad de Córdoba, Córdoba, 1994.

GAutier DAlché, Jean, "Noblesse, terre et argent au XIII" siècle: l'exemple de la famille léonaise des Moran", Histoire et société. Mélanges offerts à Georges Duby, t. 2, Publications de 1’Université de Provence, Aix-en-Provence, 1992, pp. 97-105.

Gerbet, Marie-Claude Las noblezas españolas en la Edad Media, Alianza Editorial, Madrid, 1997.

Giménez Soler, Andrés, Don Juan Manuel. Biografía y estudio crítico, Tip. La Académica de F. Martínez, Zaragoza, 1932.

GonzÁlez González, Julio, Repartimiento de Sevilla, CSIC, Madrid, 1951.

González González, Julio, Reinado y diplomas de Fernando III, Caja de Ahorros de Córdoba, Córdoba, 1980-1986, 3 vols.

GonzÁlez JimÉnez, Manuel y GonzÁlez Gómez, Antonio, El Libro del Repartimiento de Jerez de la Frontera, Instituto de Estudios Gaditanos, Cádiz, 1980.

Hernández SÁnchez, Francisco Javier, Las rentas del rey. Sociedad y fisco en el reino castellano del siglo XIII, Fundación Ramón Areces, Madrid, 1993, 2 vols.

Jular Pérez-Alfaro, Cristina, Los adelantados y merinos mayores de León (Siglos XIII-XV), Junta de Castilla y León, Valladolid, 1990.

LAFUENTE URIÉn, Asunción "Los archivos nobiliarios: formación y conservación. La Sección Nobleza del Archivo Histórico Nacional”, Estudios sobre señorío y feudalismo. Homenaje a Julio Valdeón, Esteban Sarasa y Eliseo Serrano (eds), Institución Fernando el Católico, Zaragoza, 2010, pp. 27-75.

López DAPena, Asunción, Cuentas y gastos (1292-1294) del rey don Sancho IV el Bravo (1284-1295), Caja de Ahorros de Córdoba, Córdoba, 1984.

LuCas de la Fuente, Julián D. Diego López de Haro V: magnate de Castilla, señor de Vizcaya y fundador de Bilbao, Caja de Ahorros Vizcaína, Bilbao, 1986.

LuCAs de la Fuente, Julián, Los señores de Vizcaya, siglos XI-XIV. El linaje de los Haro al frente del señorio, Librería Anticuaria Astarloa, Bilbao, 2005.

Martínez Díez, Gonzalo y GonzÁlez SÁnchez, Vidal, Monasterio cisterciense de Santa María la Real de Villamayor de los Montes, Caja de Burgos, Burgos, 2000.

Martínez Sopena, Pascual, La Tierra de Campos Occidental. Poblamiento, poder y comunidad. Del siglo X al XIII, Institución Cultural Simancas, Valladolid, 1985.

Martínez Sopena, Pascual, "La nobleza de León y Castilla en los siglos XI y XII. Un estado de la cuestión", Hispania, 185 (1993), pp. 801-822.

Mattosso, José, Livro de Linhagens do conde d. Pedro, Portugaliae Monumenta Historica. Nova série, vol II-1, Academia das Ciências, Lisboa, 1980, 2 vols.

MenÉndez Pidal, Ramón, Documentos lingüísticos de España. Reino de Castilla, CSIC, Madrid, 1966 ( $2^{\mathrm{a}}$ ed). 
MenÉndez PIdAl, Faustino La nobleza en España: ideas, estructuras, historia, BOE, Madrid, 2008.

Moxó, Salvador de, "De la nobleza vieja a la nobleza nueva. La transformación nobiliaria castellana en la Baja Edad Media", Cuadernos de Historia. Anexos de la revista Hispania, 3 (1969), pp. 1-210.

Moxó, Salvador de, "La sociedad política castellana en la época de Alfonso XI", Cuadernos de Historia. Anexos de la revista Hispania, 6 (1975), pp. 187-326.

Nieto Cumplido, Manuel, "El libro del diezmo de los donadíos de la catedral de Córdoba", Cuadernos de Estudios Medievales y Ciencias y Técnicas Historiográficas. Universidad de Granada, IV-V (1979), pp. 157-162.

Pardo de Guevara, Eduardo, Los señores de Galicia. Tenentes y condes de Lemos en la Edad Media, Fundación Pedro Barrié de la Maza, Santiago de Compostela, 2000.

PeÑa Pérez, Francisco Javier, Documentación del monasterio de San Juan de Burgos (1091-1400), J.M. Garrido Garrido, Burgos, 1983.

Pérez Carazo, Pedro, Santa María de Herce y su abadengo en la Edad Media, Instituto de Estudios Riojanos, Logroño, 2008.

Reglero de la Fuente, Carlos Manuel, Los señoríos de los Montes de Torozos. De la repoblación al Becerro de las Behetrías (siglos X-XIV), Universidad de Valladolid, Valladolid, 1993.

Rosell, Cayetano (ed.), Crónicas de los Reyes de Castilla, vol. I, Biblioteca de Autores Españoles, Madrid, 1953, T. 66.

Ruiz Gómez, Francisco, Las formas de poblamiento rural en la Bureba en la Baja Edad Media: la villa de Oña, Tesis Doctoral, Universidad Complutense de Madrid, 1988.

Salazar y Acha, Jaime de, La casa del rey en Castilla y León en la Edad Media, Centro de Estudios Políticos y Constitucionales, Madrid, 2000.

Salazar y Castro, Luis, Historia genealógica de la Casa de Lara, Imprenta Real, Madrid, 1694-1697, 4 vols.

SÁnchez de Mora, Antonio, Los Lara. Un linaje castellano de la plena Edad Media, Diputación Provincial de Burgos, Burgos, 2007.

SÁnchez SAus, Rafael, Caballería y linaje en la Sevilla medieval, Universidad de Cádiz, Cádiz, 1989.

Soria Mesa, Enrique La biblioteca genealógica de don Luis de Salazar y Castro, Universidad de Córdoba, Córdoba, 1997.

Sottomayor Pizarro, José Augusto de, As linhagens medievais portuguesas. Genealogias e estratégias (1279-1325), Centro de Estudos de Genealogia, Heráldica e História da Família, Oporto, 1999.

SuÁrez GonzÁlez, Ana (ed.), Escritura y sociedad. La nobleza, Junta de Galicia y Universidad de Santiago de Compostela, Santiago de Compostela, 2017. 


\section{Apéndice de Tablas}

Tabla 1. Tipos de documentos. Datos globales

\begin{tabular}{|l|c|c|c|c|c|}
\hline \multicolumn{1}{|c|}{ Años } & A & B & C & D & Total \\
\hline $1176-1200$ & 0 & 0 & 2 & 0 & 2 \\
\hline $1201-1225$ & 3 & 5 & 4 & 0 & 12 \\
\hline $1226-1250$ & 1 & 20 & 21 & 49 & 91 \\
\hline $1251-1275$ & 1 & 33 & 0 & 22 & 56 \\
\hline $1276-1300$ & 2 & 21 & 19 & 51 & 93 \\
\hline $1301-1325$ & 6 & 53 & 22 & 80 & 161 \\
\hline $1326-1350$ & 6 & 34 & 14 & 68 & 122 \\
\hline $1351-1369$ & 0 & 11 & 8 & 26 & 45 \\
\hline Total & 19 & 177 & 90 & 296 & 582 \\
\hline
\end{tabular}

Cuando un documento no está datado y se puede establecer un rango de fechas (por ejemplo, AHN, Clero, carp. $1664, \mathrm{n}^{\mathrm{o}} 3$, se puede datar entre 1249 y 1253 ) lo contabilizo en la primera de las fechas posibles (en el caso del ejemplo en 1249).

Tabla 2. Documentos editados e inéditos

\begin{tabular}{|l|c|c|c|c|c|}
\hline & A & B & C & D & Total \\
\hline Editados & 15 & 137 & 76 & 281 & 509 \\
\hline Inéditos & 4 & 40 & 14 & 15 & 73 \\
\hline Total & 19 & 177 & 90 & 296 & 582 \\
\hline
\end{tabular}

Tabla 3. Contenido de los documentos A y B

\begin{tabular}{|c|c|c|c|c|c|c|c|c|c|}
\hline Años & Compras & Ventas & Cambios & $\begin{array}{c}\text { Donaciones } \\
\text { otorgadas }\end{array}$ & $\begin{array}{c}\text { Donaciones } \\
\text { recibidas }\end{array}$ & Fiadores & Pleitos & Otros & Total \\
\hline $1176-1200$ & 0 & 0 & 0 & 0 & 0 & 0 & 0 & 0 & $\mathbf{0}$ \\
\hline $1201-1225$ & 0 & 2 & 0 & 2 & 2 & 0 & 1 & 1 & $\mathbf{8}$ \\
\hline $1226-1250$ & 0 & 7 & 1 & 2 & 1 & 3 & 0 & 7 & $\mathbf{2 1}$ \\
\hline $1251-1275$ & 4 & 12 & 0 & 3 & 0 & 2 & 0 & 13 & $\mathbf{3 4}$ \\
\hline $1276-1300$ & 0 & 7 & 1 & 2 & 1 & 5 & 2 & 5 & $\mathbf{2 3}$ \\
\hline $1301-1325$ & 6 & 24 & 1 & 7 & 1 & 3 & 5 & 12 & $\mathbf{5 9}$ \\
\hline $1326-1350$ & 1 & 10 & 1 & 9 & 2 & 0 & 3 & 14 & $\mathbf{4 0}$ \\
\hline $1351-1369$ & 1 & 1 & 0 & 3 & 3 & 0 & 0 & 3 & $\mathbf{1 1}$ \\
\hline Total & $\mathbf{1 2}$ & $\mathbf{6 3}$ & $\mathbf{4}$ & $\mathbf{2 8}$ & $\mathbf{1 0}$ & $\mathbf{1 3}$ & $\mathbf{1 1}$ & $\mathbf{5 5}$ & $\mathbf{1 9 6}$ \\
\hline
\end{tabular}


Tabla 4. Procedencia de los documentos. Datos globales

AHN = Archivo Histórico Nacional; AHNT = Archivo Histórico de la Nobleza de Toledo; AChV = Archivo de la Chancillería de Valladolid; ACA = Archivo de la Corona de Aragón; AGS = Archivo General de Simancas; APR $=$ Archivo del Palacio Real CSC $=$ Colección Salazar y Castro; BN = Biblioteca Nacional

\begin{tabular}{|c|c|c|c|c|c|c|}
\hline & & $\mathbf{A}$ & B & $\mathbf{C}$ & D & TOTAL \\
\hline & Editados & 15 & 137 & 76 & 281 & 509 \\
\hline & Inéditos & 4 & 40 & 14 & 15 & 73 \\
\hline & TOTAL & 19 & 177 & 90 & 296 & 582 \\
\hline & $\begin{array}{l}\text { ACA (ed. GIMÉNEZ, Don Juan } \\
\text { Manuel) }\end{array}$ & & & 2 & & 2 \\
\hline In & $\mathrm{AChV}$ & & & & 1 & 1 \\
\hline & $\begin{array}{l}\text { AGS (ed. en LuCAS, Diego López } \\
\text { de Haro) }\end{array}$ & & & 1 & & 1 \\
\hline In. & AHN, Cámara de Castilla, & & & & 2 & 2 \\
\hline In. & $\begin{array}{l}\text { Archivo Condes de Villaverde } \\
\text { (CSC) }\end{array}$ & & 4 & & 1 & 5 \\
\hline & $\begin{array}{l}\text { Archivo Condes de Villaverde (ed. } \\
\text { en DíAz Martín, Pedro I) }\end{array}$ & & 1 & & & 1 \\
\hline & $\begin{array}{l}\text { ACA (ed. en LuCAS, Diego López } \\
\text { de Haro) }\end{array}$ & & & 1 & & 1 \\
\hline In. & Archivo de San Clemente de Toledo & & 2 & & & 2 \\
\hline In. & $\begin{array}{l}\text { Archivo Duques de Frías } \\
\text { (AHNT, Frías) }\end{array}$ & & & & 1 & 1 \\
\hline & $\begin{array}{l}\text { Archivo Duques de Frías (ed. en } \\
\text { García LujÁn, Judíos) }\end{array}$ & & & & 1 & 1 \\
\hline In. & $\begin{array}{l}\text { Archivo Duques de Medinaceli } \\
\text { (CSC) }\end{array}$ & & 1 & & & 1 \\
\hline & $\begin{array}{l}\text { Archivo Duques de Nájera (ed. en } \\
\text { SALAZAR, Casa de Lara) }\end{array}$ & & & 1 & & 1 \\
\hline In. & $\begin{array}{l}\text { Archivo Duques de Osuna (AHNT, } \\
\text { Osuna) }\end{array}$ & 2 & 4 & & 1 & 7 \\
\hline In. & $\begin{array}{l}\text { Archivo Marqueses de Agoncillo } \\
\text { (AHNT, Agoncillo) }\end{array}$ & & 1 & & & 1 \\
\hline In. & $\begin{array}{l}\text { Archivo Marqueses de Poza } \\
\text { (AHNT, Poza) }\end{array}$ & & 1 & & & 1 \\
\hline & Catedral de Ávila & & & & 3 & 3 \\
\hline & Catedral de Burgos (ed.) & 2 & 8 & 2 & & 12 \\
\hline In. & Catedral de Burgos (in.) & & 4 & 4 & & 8 \\
\hline
\end{tabular}


Para Una historia de los nObles sin archivos. Sobre las fuentes documentales Para...

\begin{tabular}{|c|c|c|c|c|c|c|}
\hline & & $\mathbf{A}$ & B & $\mathbf{C}$ & D & TOTAL \\
\hline & Catedral de Calahorra & & 3 & 1 & 1 & 5 \\
\hline & Catedral de La Calzada & 1 & 2 & 3 & 3 & 9 \\
\hline & Catedral de Murcia & & 3 & 2 & & 5 \\
\hline & Catedral de Palencia & & 1 & & 2 & 3 \\
\hline & Concejo de Azcoitia & & & & 4 & 4 \\
\hline & Concejo de Azpeitia & & & & 5 & 5 \\
\hline & $\begin{array}{l}\text { Concejo de Baeza (ed. ARGOTE DE } \\
\text { Molina, Nobleza de Andalucía) }\end{array}$ & & & & 1 & 1 \\
\hline & Concejo de Bergara & & & & 7 & 7 \\
\hline & Concejo de Bilbao & & & & 1 & 1 \\
\hline & Concejo de Burgos & & & & 2 & 2 \\
\hline & Concejo de El Tiemblo, Ávila & & & & 1 & 1 \\
\hline & Concejo de Guetaria & & & & 2 & 2 \\
\hline & Concejo de Laredo & & & & 2 & 2 \\
\hline & Concejo de Logroño & & & 1 & 3 & 4 \\
\hline & Concejo de Miranda & & 3 & 1 & 4 & 8 \\
\hline & Concejo de Mondragón & & & & 4 & 4 \\
\hline & Concejo de Murcia & & & 1 & & 1 \\
\hline & Concejo de Palencia & & & & 7 & 7 \\
\hline & Concejo de Rentería & & & & 1 & 1 \\
\hline & Concejo de Salinas de Añana & & & & 1 & 1 \\
\hline & Concejo de Salvatierra & & & & 1 & 1 \\
\hline & Concejo de Santa Cruz de Campezo & & & & 1 & 1 \\
\hline & $\begin{array}{l}\text { Concejo de Sevilla (ed. en LuCAS, } \\
\text { Diego López de Haro) }\end{array}$ & & & 2 & & 2 \\
\hline & Concejo de Toledo & & & 1 & & 1 \\
\hline & Concejo de Tolosa & & 3 & & 1 & 4 \\
\hline & Concejo de Tordesillas & & & & 3 & 3 \\
\hline & Concejo de Vitoria & & & 2 & 3 & 5 \\
\hline In. & CSC (procedencia desconocida) & & 2 & & 1 & 3 \\
\hline & Hospital del Rey (ed.) & & 12 & 1 & & 13 \\
\hline In. & Hospital del Rey (in.) (APR) & & 3 & 2 & & 5 \\
\hline In. & $\begin{array}{l}\text { Hospital del Rey (in.) (Biblioteca } \\
\text { Zabálburu) }\end{array}$ & & 1 & & & 1 \\
\hline & Iglesia de San Juan de Oña & 4 & 9 & 3 & & 16 \\
\hline & Monasterio de Aguilar (ed.) & & & 1 & 1 & 2 \\
\hline
\end{tabular}




\begin{tabular}{|c|c|c|c|c|c|c|}
\hline & & $\mathbf{A}$ & B & $\mathbf{C}$ & D & TOTAL \\
\hline \multirow[t]{3}{*}{ In. } & Monasterio de Aguilar (in.) (AHN) & & 6 & 1 & 1 & 8 \\
\hline & Monasterio de Albelda & & 2 & & 1 & 3 \\
\hline & $\begin{array}{l}\text { Monasterio de Buenafuente, } \\
\text { Guadalajara (ed. en SALAZAR, Casa } \\
\text { de Lara }\end{array}$ & & & 1 & & 1 \\
\hline \multirow[t]{4}{*}{ In. } & $\begin{array}{l}\text { Monasterio de Bujedo (Becerro, } \\
\text { Diputación de Burgos) }\end{array}$ & & 1 & & & 1 \\
\hline & Monasterio de Cañas & & 1 & 2 & 5 & 8 \\
\hline & Monasterio de Entrepeñas & & 1 & & & 1 \\
\hline & Monasterio de Herce & & & & 1 & 1 \\
\hline \multirow[t]{5}{*}{ In. } & Monasterio de Herrera (AHN) & & & 2 & & 2 \\
\hline & Monasterio de Ibeas & & & & 1 & 1 \\
\hline & $\begin{array}{l}\text { Monasterio de La Vid (ed. en } \\
\text { GonZÁLEz, Fernando III) }\end{array}$ & & 1 & 1 & & 2 \\
\hline & Monasterio de Las Huelgas & 1 & 23 & 5 & 44 & 73 \\
\hline & Monasterio de Liébana & & & & 9 & 9 \\
\hline \multirow[t]{8}{*}{ In. } & Monasterio de Monfero (AHN) & & 1 & & & 1 \\
\hline & Monasterio de Nájera & & 3 & 1 & 1 & 5 \\
\hline & Monasterio de Oña & 1 & 16 & 17 & 9 & 43 \\
\hline & Monasterio de Oseira & & & & 2 & 2 \\
\hline & Monasterio de Palacios de Benaver & & & & 1 & 1 \\
\hline & Monasterio de Pinario & & 1 & & 1 & 2 \\
\hline & Monasterio de Rioseco & & 2 & 4 & 2 & 8 \\
\hline & Monasterio de Sahagún & & & & 15 & 15 \\
\hline \multirow[t]{3}{*}{ In. } & $\begin{array}{l}\text { Monasterio de San Andrés de } \\
\text { Arroyo (AHN) }\end{array}$ & & 1 & & & 1 \\
\hline & Monasterio de San Juan & & 1 & 3 & & 4 \\
\hline & Monasterio de San Millán (ed.) & & 2 & & & 2 \\
\hline In. & $\begin{array}{l}\text { Monasterio de San Millán (in.) } \\
(\mathrm{BN})\end{array}$ & & & & 2 & 2 \\
\hline \multirow[t]{5}{*}{ In. } & $\begin{array}{l}\text { Monasterio de San Millán (in.) } \\
\text { (Colección Minguella) }\end{array}$ & & 2 & & 2 & 4 \\
\hline & $\begin{array}{l}\text { Monasterio de San Román de } \\
\text { Entrepeñas }\end{array}$ & & & & 2 & 2 \\
\hline & Monasterio de San Zoilo & & & & 4 & 4 \\
\hline & Monasterio de Santillana & & & & 2 & 2 \\
\hline & Monasterio de Silos & & 6 & & & 6 \\
\hline
\end{tabular}




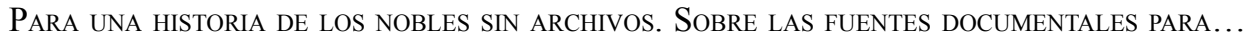

\begin{tabular}{|c|c|c|c|c|c|c|}
\hline & & $\mathbf{A}$ & B & $\mathbf{C}$ & $\mathbf{D}$ & TOTAL \\
\hline & $\begin{array}{l}\text { Monasterio de Sobrado (ed. en } \\
\text { GAIBRoIs, Sancho IV) }\end{array}$ & & 1 & & & 1 \\
\hline & Monasterio de Tórtoles & & & & 1 & 1 \\
\hline & Monasterio de Trianos & & & & 4 & 4 \\
\hline & Monasterio de Trinidad & 3 & 5 & 1 & 1 & 10 \\
\hline \multirow[t]{2}{*}{ In. } & Monasterio de Vadillo, Frías (AHN) & & & 3 & & 3 \\
\hline & $\begin{array}{l}\text { Monasterio de Vadillo, Frías } \\
\text { (ed. en MENÉNDEZ PIDAL, Documen- } \\
\text { tos lingüísticos) }\end{array}$ & & 1 & & & 1 \\
\hline \multirow[t]{5}{*}{ In. } & Monasterio de Valbuena (CSC) & & 2 & & & 2 \\
\hline & Monasterio de Valcárcel & & 1 & & 1 & 2 \\
\hline & Monasterio de Valvanera & & & & 1 & 1 \\
\hline & Monasterio de Vileña & 3 & 20 & 8 & 4 & 35 \\
\hline & $\begin{array}{l}\text { Monasterio de Villamayor de los } \\
\text { Montes }\end{array}$ & & 1 & 6 & 2 & 9 \\
\hline \multirow[t]{3}{*}{ In. } & $\begin{array}{l}\text { Monasterio de Villamayor de } \\
\text { Treviño (AHN) }\end{array}$ & & 1 & 2 & & 3 \\
\hline & Monasterio San Isidoro & & & & 4 & 4 \\
\hline & Orden de Alcántara & & & & 4 & 4 \\
\hline In. & Orden de Calatrava (AHN) & 1 & 1 & & 2 & 4 \\
\hline \multirow[t]{4}{*}{ In. } & Orden de Calatrava (CSC) & & 1 & & 1 & 2 \\
\hline & $\begin{array}{l}\text { Orden de Calatrava (ed. en } \\
\text { Bulario) }\end{array}$ & & & & 3 & 3 \\
\hline & $\begin{array}{l}\text { Orden de Calatrava (ed. en } \\
\text { Fernando IV) }\end{array}$ & & 1 & & & 1 \\
\hline & Orden de San Juan & & & & 3 & 3 \\
\hline \multirow[t]{8}{*}{ In. } & Orden de Santiago (AHN) & 1 & 1 & & & 2 \\
\hline & $\begin{array}{l}\text { Procedencia desconocida (SALAZAR, } \\
\text { Casa de Lara) }\end{array}$ & & 2 & & & 2 \\
\hline & Alfonso XI & & & & 20 & 20 \\
\hline & Fernando III & & & & 27 & 27 \\
\hline & Fernando IV & & 1 & & 33 & 34 \\
\hline & Pedro I & & & 1 & & 1 \\
\hline & Sancho IV & & & & 8 & 8 \\
\hline & TOTAL & 19 & 177 & 90 & 296 & 582 \\
\hline
\end{tabular}


Tabla 5. Procedencia de los documentos. Archivos nobiliarios y otros.

AHN = Archivo Histórico Nacional; $\mathrm{AChV}=$ Archivo de la Chancillería de Valladolid; ACA = Archivo de la Corona de Aragón; AGS = Archivo General de Simancas; CSC = Colección Salazar y Castro.

\begin{tabular}{|c|c|c|c|c|c|}
\hline & $\mathbf{A}$ & B & $\mathbf{C}$ & D & TOTAL \\
\hline Editados & & 3 & 5 & 1 & 9 \\
\hline Inéditos & 2 & 13 & & 7 & 22 \\
\hline TOTAL & & & & & 31 \\
\hline \multicolumn{6}{|c|}{ Archivos nobiliarios } \\
\hline Archivo Duques del Infantado & 2 & 4 & & 1 & 7 \\
\hline Archivo Condes de Villaverde & & 5 & & 1 & 6 \\
\hline Archivo Duques de Nájera & & & 1 & & 1 \\
\hline Archivo Duques de Frías & & & & 2 & 2 \\
\hline Archivo Duques de Medinaceli & & 1 & & & 1 \\
\hline Archivo Marqueses de Agoncillo & & 1 & & & 1 \\
\hline Archivo Marqueses de Poza & & 1 & & & 1 \\
\hline \multicolumn{6}{|c|}{ Otros } \\
\hline $\mathrm{ACA}$ & & & 3 & & 3 \\
\hline CSC (procedencia desconocida) & & 2 & & 1 & 3 \\
\hline AHN, Cámara de Castilla, & & & & 2 & 2 \\
\hline $\begin{array}{l}\text { Procedencia desconocida (SAlAZAR, } \\
\text { Casa de Lara) }\end{array}$ & & 2 & & & 2 \\
\hline $\mathrm{AChV}$ & & & & 1 & 1 \\
\hline AGS & & & 1 & & 1 \\
\hline
\end{tabular}

Tabla 6. Procedencia de los documentos. Catedrales (incluye una parroquia).

\begin{tabular}{|l|c|c|c|c|c|}
\hline & A & B & C & D & TOTAL \\
\hline Editados & 7 & 26 & 11 & 9 & $\mathbf{5 3}$ \\
\hline Inéditos & & 4 & 4 & & $\mathbf{8}$ \\
\hline TOTAL & 7 & 30 & 15 & 9 & $\mathbf{6 1}$ \\
\hline & & & & & \\
\hline Catedral de Burgos & 2 & 12 & 6 & & $\mathbf{2 0}$ \\
\hline Iglesia de San Juan de Oña & 4 & 9 & 3 & & $\mathbf{1 6}$ \\
\hline Catedral de La Calzada & 1 & 2 & 3 & 3 & $\mathbf{9}$ \\
\hline Catedral de Calahorra & & 3 & 1 & 1 & $\mathbf{5}$ \\
\hline Catedral de Murcia & & 3 & 2 & & $\mathbf{5}$ \\
\hline Catedral de Ávila & & & & 3 & $\mathbf{3}$ \\
\hline Catedral de Palencia & & 1 & & 2 & $\mathbf{3}$ \\
\hline
\end{tabular}


Tabla 7. Procedencia de los documentos. Concejos

\begin{tabular}{|l|c|c|c|c|c|}
\hline & A & B & C & D & TOTAL \\
\hline Editados & 0 & 6 & 8 & 54 & $\mathbf{6 8}$ \\
\hline Inéditos & & & & & \\
\hline TOTAL & & & & & $\mathbf{6 8}$ \\
\hline & & & & & \\
\hline Concejo de Miranda & & 3 & 1 & 4 & $\mathbf{8}$ \\
\hline Concejo de Bergara & & & & 7 & $\mathbf{7}$ \\
\hline Concejo de Palencia & & & & 7 & $\mathbf{7}$ \\
\hline Concejo de Azpeitia & & & & 5 & $\mathbf{5}$ \\
\hline Concejo de Vitoria & & & 2 & 3 & $\mathbf{5}$ \\
\hline Concejo de Azcoitia & & & & 4 & $\mathbf{4}$ \\
\hline Concejo de Logroño & & & 1 & 3 & $\mathbf{4}$ \\
\hline Concejo de Mondragón & & & & 4 & $\mathbf{4}$ \\
\hline Concejo de Tolosa & & 3 & & 1 & $\mathbf{4}$ \\
\hline Concejo de Tordesillas & & & & 3 & $\mathbf{3}$ \\
\hline Concejo de Burgos & & & & 2 & $\mathbf{2}$ \\
\hline Concejo de Guetaria & & & & 2 & $\mathbf{2}$ \\
\hline Concejo de Laredo & & & & 2 & $\mathbf{2}$ \\
\hline Concejo de Sevilla & & & & 1 & $\mathbf{2}$ \\
\hline Concejo de Baeza & & & & 1 & $\mathbf{1}$ \\
\hline Concejo de Bilbao & & & & 1 & $\mathbf{1}$ \\
\hline Concejo de El Tiemblo, Ávila & & & & 1 & $\mathbf{1}$ \\
\hline Concejo de Murcia & & & & 1 \\
\hline Concejo de Rentería & & & & 1 \\
\hline Concejo de Salinas de Añana & & & & 1 \\
\hline Concejo de Salvatierra & & & & 1 & $\mathbf{1}$ \\
\hline Concejo de Santa Cruz de Campezo & & & & & \\
\hline Concejo de Toledo & & & & & 1 \\
\hline
\end{tabular}


Tabla 8. Procedencia de los documentos. Monasterios (incluye un hospital)

\begin{tabular}{|c|c|c|c|c|c|}
\hline & $\mathbf{A}$ & B & $\mathbf{C}$ & D & TOTAL \\
\hline Editados & 8 & 100 & 51 & 119 & 278 \\
\hline Inéditos & 0 & 20 & 10 & 5 & 35 \\
\hline TOTAL & 8 & 118 & 61 & 124 & 313 \\
\hline Monasterio de Las Huelgas & 1 & 23 & 5 & 44 & 73 \\
\hline Monasterio de Oña & 1 & 16 & 17 & 9 & 43 \\
\hline Monasterio de Vileña & 3 & 20 & 8 & 4 & 35 \\
\hline Hospital del Rey & & 16 & 3 & & 19 \\
\hline Monasterio de Sahagún & & & & 15 & 15 \\
\hline Monasterio de Aguilar & & 6 & 2 & 2 & 10 \\
\hline Monasterio de Trinidad & 3 & 5 & 1 & 1 & 10 \\
\hline Monasterio de Liébana & & & & 9 & 9 \\
\hline $\begin{array}{l}\text { Monasterio de Villamayor de los } \\
\text { Montes }\end{array}$ & & 1 & 6 & 2 & 9 \\
\hline Monasterio de Cañas & & 1 & 2 & 5 & 8 \\
\hline Monasterio de Rioseco & & 2 & 4 & 2 & 8 \\
\hline Monasterio de San Millán & & 4 & & 4 & 8 \\
\hline Monasterio de Silos & & 6 & & & 6 \\
\hline Monasterio de Nájera & & 3 & 1 & 1 & 5 \\
\hline Monasterio de San Juan & & 1 & 3 & & 4 \\
\hline Monasterio de San Zoilo & & & & 4 & 4 \\
\hline Monasterio de Trianos & & & & 4 & 4 \\
\hline Monasterio de Vadillo, Frías & & 1 & 3 & & 4 \\
\hline Monasterio San Isidoro & & & & 4 & 4 \\
\hline Monasterio de Albelda & & 2 & & 1 & 3 \\
\hline Monasterio de Villamayor de Treviño & & 1 & 2 & & 3 \\
\hline Monasterio de Herrera & & & 2 & & 2 \\
\hline Monasterio de La Vid & & 1 & 1 & & 2 \\
\hline Monasterio de Oseira & & & & 2 & 2 \\
\hline Monasterio de Pinario & & 1 & & 1 & 2 \\
\hline $\begin{array}{l}\text { Monasterio de San Clemente de } \\
\text { Toledo }\end{array}$ & & 2 & & & 2 \\
\hline $\begin{array}{l}\text { Monasterio de San Román de } \\
\text { Entrepeñas }\end{array}$ & & & & 2 & 2 \\
\hline Monasterio de Santillana & & & & 2 & 2 \\
\hline Monasterio de Valbuena & & 2 & & & 2 \\
\hline Monasterio de Valcárcel & & 1 & & 1 & 2 \\
\hline $\begin{array}{l}\text { Monasterio de Buenafuente, } \\
\text { Guadalajara }\end{array}$ & & & 1 & & 1 \\
\hline Monasterio de Bujedo & & 1 & & & 1 \\
\hline Monasterio de Entrepeñas & & 1 & & & 1 \\
\hline
\end{tabular}




\begin{tabular}{|l|c|c|c|c|c|}
\hline Monasterio de Herce & & & & 1 & $\mathbf{1}$ \\
\hline Monasterio de Ibeas & & & & 1 & $\mathbf{1}$ \\
\hline Monasterio de Monfero & & 1 & & & $\mathbf{1}$ \\
\hline Monasterio de Palacios de Benaver & & & & 1 & $\mathbf{1}$ \\
\hline Monasterio de San Andrés de Arroyo & & 1 & & & $\mathbf{1}$ \\
\hline Monasterio de Sobrado & & 1 & & & $\mathbf{1}$ \\
\hline Monasterio de Tórtoles & & & & 1 & $\mathbf{1}$ \\
\hline Monasterio de Valvanera & & & & 1 & $\mathbf{1}$ \\
\hline
\end{tabular}

Tabla 9. Procedencia de los documentos. Órdenes militares.

\begin{tabular}{|l|c|c|c|c|c|}
\hline & A & B & C & D & TOTAL \\
\hline Editados & & 1 & & 10 & $\mathbf{1 1}$ \\
\hline Inéditos & 2 & 3 & & 3 & $\mathbf{8}$ \\
\hline TOTAL & 2 & 4 & & 13 & $\mathbf{1 9}$ \\
\hline & & & & & \\
\hline Orden de Calatrava & 1 & 3 & & 6 & $\mathbf{1 0}$ \\
\hline Orden de Alcántara & & & & 4 & $\mathbf{4}$ \\
\hline Orden de San Juan & & & & 3 & $\mathbf{3}$ \\
\hline Orden de Santiago & 1 & 1 & & & $\mathbf{2}$ \\
\hline
\end{tabular}

Tabla 10. Procedencia de los documentos. Colecciones regias

\begin{tabular}{|l|c|c|c|c|c|}
\hline & A & B & C & D & TOTAL \\
\hline Editados & & 1 & 1 & 88 & $\mathbf{9 0}$ \\
\hline Inéditos & & & & & \\
\hline TOTAL & & 1 & 1 & 88 & $\mathbf{9 0}$ \\
\hline & & & & & \\
\hline Fernando III & & & & 27 & $\mathbf{2 7}$ \\
\hline Sancho IV & & & & 8 & $\mathbf{8}$ \\
\hline Fernando IV & & 1 & & 33 & $\mathbf{3 4}$ \\
\hline Alfonso XI & & & & 20 & $\mathbf{2 0}$ \\
\hline Pedro I & & & 1 & & $\mathbf{1}$ \\
\hline
\end{tabular}

